\title{
Ficção científica e sua contribuição para a história da ciência: as

\author{
possibilidades didáticas do cinema
}

\author{
Angélica Antonechen Colombo \\ Instituto Federal do Paraná \\ (IFPR - Campus Jaguariaíva) \\ (angelica.colombo@ifpr.edu.br)
}

\begin{abstract}
Resumo: Filmes de ficção científica têm ajudado professores para uma melhor reflexão dos conceitos científicos e tecnológicos. Como obra artística, não se pode esperar do filme a pretensão de ensinar didaticamente conteúdos pré-estabelecidos. Entretanto, ensinar não é apenas explicar, mas fundamentalmente problematizar. Nesse sentido, o filme, além de ser um ponto de partida gerador de debates e aprendizagens de múltiplos conteúdos, é também uma nova forma de abordagem da história e filosofia da ciência e da tecnologia, quando utiliza o gênero de ficção científica. Portanto, este trabalho pretende mostrar que a ficção científica, com a multiplicidade de visões futuras que a caracteriza, auxilia professores e alunos a trabalhar criticamente os componentes curriculares de Ciências. A proposta visa oferecer subsídios pedagógicos para o trabalho de conceitos científicos e tecnológicos e também de sua história, por meio de produções cinematográficas de ficção científica. Diante do exposto, este trabalho, de cunho qualitativo, destina-se a investigar e oferecer ferramentas para que os professores da área de Ciências utilizem o cinema em suas práticas pedagógicas.
\end{abstract}

Palavras-chave: História da Ciência; Didática; Ficção Científica.

\section{Science fiction and its contribution to the history of science: the possibilities of didactics of cinema}

Abstract: Sci-fi movies have helped teachers to better reflect on scientific and technological concepts. As an artistic work, It can not be expected from the movie to teach didactically pre-established contents. However, teaching is not just explain, but fundamentally problematize. In this sense, the film, besides being a starting point that generates debates and learning of multiple contents, is also a new approach to the history and philosophy of science and technology, when it uses the science fiction genre.Therefore, this work intends to show that science fiction, with its multiplicity of future visions, helps teachers and students to work critically on the curricular components of Science. The proposal aims at providing support-training requirements for the work of scientific concepts and technological and of its history through cinema productions of science fiction. Given that, the purpose of this qualitative study is to investigate and provide tools for teachers in the area of Science to use Cinema in their pedagogical practices.

Keywords: History of science; didactics; science fiction.

\section{INTRODUÇÃO}

Durante a Revolução Científica (período), as pessoas mais letradas conheceram a possibilidade de se pensar em uma nova estrutura de mundo. Os artistas dessa época, fascinados por esses novos ideais científicos, reproduziram em suas obras a imensidão do cosmos que a ciência mostrou, assim como 
aconteceu no Barroco, com a ideia de infinito vistas nas dobras das obras de arte, decorrentes da invenção do cálculo infinitesimal Leibniziano, como declara Eco (1991, p. 157):

[...] a poética do Barroco reage a uma nova visão do cosmo introduzida pela revolução copernicana, sugerida quase em termos figurativos pela descoberta da elipticidade das órbitas planetárias por Kepler - descoberta que põe em crise a posição privilegiada do círculo como símbolo de perfeição cósmica. Assim como a pluriperspectiva da construção barroca se ressente desta concepção - não mais geocêntrica e, portanto, não mais antropocêntrica - de um universo ampliado rumo ao infinito [...].

Em cada época, marcada por transformações na história da ciência, a construção de um imaginário científico se alicerçava com o auxílio das produções literárias, artísticas, posteriormente cinematográficas e até midiáticas.

Quando vemos uma produção cinematográfica sobre viagens espaciais, ou sobre o avanço da medicina, nos questionamos sobre a veracidade dos fatos exibidos no filme, ou aceitamos aquilo como ficção científica, longe do alcance da humanidade? Quando não estamos assistindo filmes biográficos, aqueles que tratam de temas mais estranhos à nossa realidade, nos fazem pensar se poderiam ser reais todos os detalhes que a história nos trouxe. Um filme, um livro ou qualquer outra produção que se utiliza da ciência para permear os seus enredos pode ou não trabalhar com fatos científicos. Nesse âmbito, serem reais ou não vai de encontro com os questionamentos que temos dos avanços da ciência, mas isso só acontece pois estamos imersos em um imaginário científico que nos foi oferecido também por meio dessas produções cinematográficas (PIASSI, 2007).

Os aparatos cinematográficos, sabe-se, foram usados muito antes de serem aparelhos de exibição de filmes. Utilizados por Jules Janssen para reproduzir a trajetória do planeta Vênus, inspirou-se no trabalho de Edward Muybridge, sendo prontamente usado para pesquisas científicas, principalmente no campo do estudo do movimento.

Filmes de ficção científica têm ajudado professores na melhor reflexão dos conceitos científicos; para o professor, o ambiente de diversão criado pelos filmes de ficção é desencadeador de curiosidades e, assim, eles podem começar a elaborar questões e buscar respostas a respeito dos fatos científicos, tendo, dessa maneira, uma atitude ativa em relação ao conhecimento tradicional. 
Nas formas tecnológicas culturais tradicionais, como a fotografia e o cinema, existem modalidades específicas de organização que delineiam a experiência humana e que provocam os olhos e o pensamento, a fim de fazer com que os espectadores cheguem ao produto final que cada um subjetivamente irá conhecer, por meio de uma fusão de entendimento e emoção.

O cinema conta a história de sua época, reconta a história do passado e pode prever a história futura. Levar filmes que contam episódios da história da ciência pode ser valioso no que diz respeito à verdadeira compreensão dessa história. Assim, os filmes podem ser um ótimo recurso didático quando determinados aspectos são utilizados para propor questões, ampliar o conhecimento, motivar o estudo de um tema e facilitar a compreensão de alguns conceitos.

É por meio da contemplação participativa que foi trazida pelo cinema que os aparatos tecnológicos são responsáveis por proporcionar uma novíssima maneira de perceber e apreender a realidade, possibilitando assim novas formas mediadoras de práticas pedagógicas. Partindo deste contexto, torna-se interessante e compreensível tomar como proposta a análise dos meios de comunicação e seus possíveis usos em ambientes de ensino e de aprendizagem.

\section{UM NOVO PARADIGMA, UMA NOVA RACIONALIDADE: UM NOVO CAPÍTULO PARA A HISTÓRIA DA CIÊNCIA}

Albert Einstein, em sua Teoria da Relatividade Geral, publicada em 1915, descobriu que os objetos que se movimentam no universo produzem ondulações no espaço-tempo e que estas se propagam pelo espaço. Predizia assim as ondas gravitacionais, que são pequenas ondulações provocadas no tecido do espaçotempo que se propagam no universo à velocidade da luz, mas demonstrar de maneira direta sua existência era um dos desafios pendentes da ciência. No dia 11 de fevereiro de 2016, os responsáveis pelo Observatório da Interferometria a Laser de Ondas Gravitacionais (LIGO), patrocinado pela Fundação Nacional de Ciências dos Estados Unidos da América, anunciou que seus cientistas captaram as ondas produzidas pelo choque de dois buracos negros, a primeira detecção direta que confirma a teoria de Albert Einstein. Esse acontecimento recente faz parte de uma 
série de fatos que se confirmam e ficam registrados na história da ciência moderna, mais especificamente na história da física moderna e da astronomia gravitacional.

Fatos como esse aconteceram em um passado não muito distante de nossa atualidade e também causaram frenesi entre os mais leigos no assunto, mas principalmente entre os integrantes da comunidade científica. Um fato que pode mudar a forma como os homens conhecem a natureza faz com que o curso da história da humanidade mude seu trajeto. Podemos dar um exemplo do passado, como os estudos de Galileu sobre astronomia, ou a criação das leis de Newton e sua investigação sobre a teoria da gravidade (ROSSI, 2001).

$\mathrm{Na}$ filosofia da ciência, muitos filósofos, principalmente na virada do século $\mathrm{XX}$, como no famoso Círculo de Viena, analisaram esses fatos ocorridos no campo científico e levantaram indagações sobre o que chamamos de paradigmas científicos. Diante de um novo paradigma científico que emerge na história, os questionamentos a respeito da natureza, do conhecimento e da veracidade das investigações científicas tornam-se temas examinados exaustivamente pela filosofia da ciência.

Para Massoni (2005), autores célebres como Kuhn, Popper, Feyerabend e Bachelard observam a ideia de que há uma crise do paradigma conhecido como científico-moderno, e que parece emergir uma nova concepção de ciência e conhecimento advinda das mais novas explorações da ciência ocidental. Assim como é possível pensar em uma quebra de paradigma que resultará da detecção da existência das ondas gravitacionais previstas por Einstein, outros acontecimentos na história da ciência contribuíram para essa mudança de paradigma, principalmente no que diz respeito a ciência moderna.

O filósofo da ciência, Thomas Kuhn (1991), tem-se mostrado bastante relevante para as discussões realizadas em filosofia da ciência na contemporaneidade, ressaltando as mudanças de paradigmas decorrentes dos acontecimentos da ciência. De maneira breve, explicaremos como esse filósofo lidou com o tema da crise do paradigma científico a fim de compreendermos como a imagem da ciência é construída.

Para Kuhn (1991, p.13), as ciências evoluem através de paradigmas. O autor afirma que esses paradigmas são "as realizações científicas universalmente reconhecidas que durante algum tempo fornecem problemas e soluções modelares para uma comunidade de praticantes de uma ciência”. Mais adiante esclarece que 
"no seu uso estabelecido, um paradigma é um modelo ou padrão aceito" pelos praticantes de uma ciência e que permite a explicação de certos aspectos da realidade (1991, p. 43). Kuhn esclarece que o desenvolvimento da ciência não é resultado de dispositivos de continuidade, mas sim de ruptura, e nesse sentido o filósofo vai tentar explicitar suas teorias epistemológicas em um contato mais direto com a história da ciência.

A produção da ciência não é mais concebida como algo restrito à comunidade científica, e sim como o resultado da interação com outros fatores, como o da representação pública da ciência. Deste modo, relacionando as noções de paradigmas científicos à construção da história da ciência e ao desenvolvimento do imaginário científico, consideramos essa relação como algo mais amplo, que envolve várias formas de representação sobre a ciência pós-moderna.

Rossi (2001) afirma que a ciência, a partir do lluminismo, adquiriu uma nova perspectiva ao se colocar a serviço da sociedade e do homem. Dessa forma, a ciência moderna, e atualmente a ciência contemporânea, substituiu a mera erudição e especulação pela previsão racional dos fenômenos, colocando esse conhecimento a serviço da humanidade e o decorrente progresso das ciências, que beneficia a sociedade como um todo contribuindo para aumentar a confiança na atividade científica.

No percurso histórico da ciência, diferentes fontes foram utilizadas para compreender os fenômenos da natureza e construir conhecimento. Essa construção se estabeleceu de forma singular nos diferentes contextos históricos e comunidades científicas de cada época, sendo caracterizada por métodos distintos de se fazer ciência, os quais se tornaram valiosas formas de legitimação da produção de conhecimento da ciência, assim como afirma Kuhn (1991). Para ter significado, a linguagem científica deve ter, necessariamente, uma relação com o real, assim a construção da história da ciência contemporânea tem uma maior conexão com a divulgação científica, a mídia e o desenvolvimento da era da informação. Isso faz com que o conhecimento de fatos científicos fora da comunidade torna-se cada vez mais comum em nossa atualidade.

Os temas científicos garantiram espaço na produção cultural, uma vez que boa parte dos principais elementos que compõem o imaginário científico contemporâneo tem suas raízes ainda na Revolução Científica e principalmente no lluminismo. O pensamento científico moderno consolidou-se com a revelação das 
leis da mecânica de Isaac Newton, que moldaram a imagem do cientista no seio cultural da sociedade da época. Londres, por exemplo, caracterizou-se como berço das obras literárias e artísticas que retratavam muito bem o desenvolvimento da Ciência nos laboratórios (ROSSI, 2001).

Obras como o Fausto (1808), de Goethe, e Experimento com um Pássaro numa Bomba de Ar (1768), de Joseph Wright, de Derby (Reino Unido), ilustram a racionalidade iluminista da época, ou seja, a dominação da natureza pelo homem, levando às pessoas a ideia de que a ciência e a busca pelo conhecimento dariam ao homem o controle da realidade. No século XIX e na virada do século $X X$, ideais científico-tecnológicos tornam-se um tema presente nas obras literárias e posteriormente cinematográficas (GOMBRICH, 2008).

\section{FICÇÃO CIENTÍFICA E SUA CONTRIBUIÇÃO PARA A HISTÓRIA}

Foi ainda em 1818, um pouco antes das reviravoltas científicas da virada do século XX, como a Teoria da Relatividade de Einstein, que surgiu no seio da literatura um novo gênero de produção literária advinda do Romantismo Gótico. A produção de Mary Shelley, Frankenstein, ou, o Moderno Prometeu inaugurou o chamado gênero de ficção científica na literatura do século XIX, Júlio Verne, outro nome importante da ficção científica, lança em 1864 a obra Viagem ao Centro da Terra, em 1870 Vinte Mil Léguas Submarinas e em 1873 a obra A Volta ao Mundo em 80 dias, clássicos da ficção científica. Com a sociedade vivendo grandes transformações decorrentes da Revolução Industrial e adaptando-se a uma forma de vida mais frenética, os questionamentos a respeito da vida, da realidade, do avanço da humanidade com bases científicas tornaram-se temas presentes nas obras literárias desse século, afinal, como definiu Isaac Asimov, a ficção científica é o "ramo da literatura que trata das respostas do homem às mudanças ocorridas ao nível da ciência e da tecnologia" (ASIMOV, 1984, p. 46).

Com o surgimento da fotografia e posteriormente do cinema, a ciência e a arte andavam de mãos dadas. O cinema se estreitava com a ciência desde seus primórdios, pois a técnica de criar imagens em movimento, já em fins do século XVIII, vinha se multiplicando. Os primeiros estudos sobre o registro do movimento em geral se deram em diferentes sentidos, tanto sobre a expectativa de verificar a 
trajetória de planetas, quanto de observar, no mundo animado, detalhes da marcha de animais e do próprio ser humano.

Com recursos às obras de ficção científica que eram reproduzidas rapidamente, e o cinema em desenvolvimento, o cineasta francês Georges Méliès foi pioneiro na exploração das possibilidades cinematográficas e inventou truques, movimentos de câmera e efeitos especiais, além de usar a luz artificial. Sua obraprima Le voyage dans la lune (Viagem à Lua), de 1902, baseada em um livro de ficção científica, é um dos primeiros registros cinematográficos em que aparecem as primeiras representações de cientistas no cinema. Outro cineasta que inaugurou na história do cinema o gênero de filmes de ficção científica foi Fritz Lang com o célebre Metrópolis de 1927 (MACARELLO, 2006).

O gênero de ficção científica, principalmente nos cinemas, retrata os problemas caóticos ligados à natureza, produzindo na maioria das vezes cenas de futuros distópicos resultantes da força do homem em relação à natureza, porém de maneira mais realista, busca também - mesmo de modo ficcional -, reproduzir os conceitos e feitos científicos de uma época. Desse modo, as obras de ficção científica são aquelas que tomam o conhecimento produzido pelas ciências e o reproduz prevendo quais podem ser seus próximos passos. Apropriam-se do conhecimento científico aceito e aplicam-no em um novo contexto para mostrar suas implicações ou constroem um mundo em torno de um conjunto particular de fatos (ALLEN, 1974, p. 22). Piassi (2007) ainda afirma:

Com o desenvolvimento científico e com a influência que ele adquiriu em nossas vidas, a ficção científica passou a ser um dos principais meios de expressar estes desejos de transcendência humana através das possiblidades trazidas pela ciência. A ficção científica expressa, através de suas páginas escritas e de suas imagens nas telas do cinema e da TV, muito mais que aventuras espaciais, combates com espadas lasers e monstros feiosos e bizarros: expressa as preocupações, medos, desejos e questionamentos humanos frente ao universo de possibilidades que a cultura técnicocientífica de nossos tempos colocou diante cada um de nós. Em outras palavras, questões humanas, que as nossas salas de aula ainda insistem em desvincular do ensino de ciências. (p. 30-31)

Assim, as narrativas de ficção científica dedicam-se a especular sobre a vida futura, imaginando os desdobramentos da ciência, construindo uma associação direta com a realidade científica. Ao lidar com estes dois mundos, a ficção científica 
abre o acesso a diferentes produções da Ciência, oportunizando, com base em uma obra artística, o contato com as transformações que o homem da Ciência vem imprimindo ao mundo.

\section{APROXIMANDO DUAS CULTURAS: CIÊNCIA E CINEMA}

Aproximar a ciência das produções culturais não é algo tão simples no que diz respeito à história da ciência e principalmente ao ensino de ciências. Poucos autores se atreveram a propor essa empreitada, pois áreas tão diversas parecem estar muito distantes uma da outra, porém, como vimos em poucos exemplos citados no decorrer desse texto, não estão assim tão longe e podem sim influenciar uma a outra.

Parece simples pensar que a ficção científica é a que mais se aproxima da produção da ciência de fato, mas há diversas outras produções culturais, como as artes plásticas, literatura, cinema, por exemplo, que podem ou estão relacionadas intimamente com a ciência, basta encontrar esse ponto de encontro e abusar das reflexões que possam surgir, assim como declara João Zanetic (2006, p. 56):

[...] sempre aprendi muito por meio da leitura das grandes obras de cientistas, romancistas, poetas, filósofos e historiadores, mesmo quando distantes de suas especialidades mais específicas, não como se fossem "donos da verdade", mas como indivíduos de extrema sensibilidade que produziram reflexões que podem nos auxiliar no diálogo inteligente com o espaço-tempo em que vivemos.

Buscar um significado para a aprendizagem em outros instrumentos que não somente os livros didáticos ou os manuais pedagógicos foi uma postura de vários mestres e tutores do decorrer da história da educação. Durante muitos anos havia pouquíssimo ou quase nenhum manual didático que guiaria o mestre em seus ensinamentos. Muitos livros de literatura foram utilizados para educar moralmente os jovens, por exemplo. Atualmente, com a literatura cada vez mais crescente e o cinema se influenciando pela literatura e também criando seu próprio mundo, há muito a contribuir com o processo de ensino e aprendizagem de crianças, jovens e também de professores. 
Por isso, João Zanetic foi um dos pioneiros no Brasil ao aproximar Física e Literatura em sua tese de doutorado. Outros teóricos buscaram também aproximar essas duas culturas, a ciência e a arte, de diversas maneiras que geraram muitos frutos para a educação em ciências. Como discutido no tópico anterior, é inaceitável desconsiderar os aspectos culturais da ciência, pois ao fazer isso estamos reduzindo todo conhecimento científico a um produto pronto, a uma verdade que deve ser aceitável para todos. Desse modo, o ato de educar deveria ser um ato cultural, como afirma Zanetic (1984).

Aproximar-se das fronteiras entre essas duas culturas, a arte e a ciência, é um tema de discussão mais complexo do que parece. Autores como Jacob Bronowski (1998, p. 20) escreveram sobre esse tema e defendem tal aproximação, principalmente entre a ciência e a poesia:

\begin{abstract}
A imaginação nos atinge e nos penetra de formas diferentes na ciência e na poesia. Na ciência, ela organiza nossa experiência em leis, sobre as quais baseamos nossas ações futuras. A poesia, porém, é outro modo de conhecimento, em que comungamos com o poeta, penetrando diretamente na sua experiência e na totalidade da experiência humana.
\end{abstract}

Mas o que seriam essas duas culturas? Por que criamos essa fronteira entre duas grandes áreas do conhecimento? Para explicar melhor o termo e compreendermos a trajetória desse debate recorremos a Charles Snow (1995), quando cunhou o termo Duas Culturas em uma palestra na University of Cambridge, sendo publicada em 1959. Em tal palestra, Snow faz uma crítica aos literatos pelo seu distanciamento dos conhecimentos científicos, lamentando que os intelectuais não possuíam conhecimento das leis da termodinâmica, o equivalente ao conhecimento das obras de Shakespeare na ciência, e afirmou:

Essa polarização é pura perda para todos nós. Para nós como pessoas, e para a nossa sociedade. É ao mesmo tempo perda prática, perda intelectual e perda criativa, e repito que é errôneo imaginar que esses três aspectos são claramente separáveis. (SNOW, 1995, p. 29)

A palestra obviamente foi fruto de muita polêmica, mas não deixou de transmitir uma mensagem importante a respeito do distanciamento que existe entre essas duas culturas. E não são somente os intelectuais literatos que se distanciam 
do conhecimento científico, mas também muitos cientistas se distanciam dos conhecimentos das Humanidades, quando estão preocupados em conhecer todas as leis das Ciências Naturais. Herança de um Positivismo, a partir da Revolução Científica, esse distanciamento passa a ter importância principalmente no que diz respeito à história da ciência e a sua autonomia em relação a outros aspectos sociais e culturais e principalmente ao que tange ao ensino de ciências.

Ao olharmos para o passado, na Antiguidade, na Renascença, por exemplo, podemos observar uma proximidade natural dessas duas culturas na produção de conhecimento, que não eram vistas como independentes uma da outra:

Para Pitágoras e seus seguidores, os números eram a chave para o universo e a música era inseparável dos números [...]. Cláudio Ptolomeu, o principal astrônomo da Antiguidade, era também notável compositor. Leis e proporções matemáticas eram consideradas a sustentação tanto dos intervalos musicais quanto dos corpos celestes e acreditava-se que certos planetas, a distância entre estes e seus movimentos correspondiam a certas notas, intervalos e escalas musicais. (PINHEIRO, 2011 apud ENGLAND, 2009, p. 5)

Por conseguinte, sabemos que o ato de imaginar não se encontra apenas no ato de criar cenários e mundos literários, ou lindas peças teatrais, ou obras plásticas riquíssimas, mas a imaginação, como já mencionado, também é o instrumento no qual o cientista se apoia para criar suas hipóteses e para testar suas teorias. Por isso, é preciso retomar esse interesse amplo que sempre existiu entre os sábios, a arte e a ciência são as formas de conhecimento que conseguem, cada uma a seu jeito, explicar a realidade.

Quando separamos a imaginação do ato de criar, não somente produtos artísticos, mas também novas teorias para a ciência, as limitamos à uma categorização pragmática, pois sabemos que ao entrar em crise a ciência não depende somente do puro racionalismo a fim de encontrar mecanismos para sair da crise, ela precisa usar de maneira muito sábia a imaginação para criar novos meios de se fazer ciência. Bronowski (1998, p. 38-39) defende:

Muitas pessoas pensam que o raciocínio, e, portanto, a ciência, é uma atividade distinta da imaginação - uma falácia que devemos desprezar. (...) Prejudicamos a educação das crianças quando as habituamos a separar a razão da imaginação, apenas pela conveniência do horário escolar. Porque a imaginação não se limita 
às explosões da fantasia, ela é sempre a manipulação mental do que está ausente dos sentidos, mediante o uso de imagens, palavras ou outros símbolos. A imaginação é sempre um processo experimental, seja com conceitos lógicos ou com a matéria-prima da arte.

No ensino de ciências, e principalmente quando educamos as crianças e os jovens, quando os impedimos de usarem a imaginação para poder criar suas próprias conclusões dos conteúdos ensinados, ou até mesmo, as conclusões sobre as suas visões a respeito da realidade e da natureza, estamos os afastando cada vez mais do ato de criar, não somente na ciência, mas em todas as outras áreas.

Grandes sábios da Antiguidade usaram da forte imaginação para pensar o cosmos. Demócrito (460 - 370 a.C.) fala do átomo, antes mesmo de saber sua estrutura e de imaginar do tanto que atualmente buscamos conhecê-lo. Kepler, em sua obra Harmonices Mundi (1619), imagina que o universo e os planetas possuem sons próprios que são responsáveis pela harmonia do mundo. Esses e muitos outros usaram da imaginação para criar uma interpretação racional para a realidade em que viviam, e uma criança e um jovem deve fazer o mesmo, não podemos omitir isso deles.

Um autor que discute o papel da imaginação na arte e na ciência é GillesGaston Granger, quando associa o processo criativo e a imaginação a essas duas grandes áreas de conhecimento. Em seus escritos, Granger afirma que observa "uma atividade profunda da criação poética e da criação científica" (1998, p. 7). Nesse caso, o autor afirma que a imaginação tem o papel de representar por meio de imagens os objetos do mundo tanto para a ciência, de modo abstrato, quanto para a arte de modo sensível.

Há então uma preocupação de alguns autores, educadores, historiadores de que construir essa fronteira entre duas áreas que correspondem à produção cultural humana e que dizem muito sobre a realidade, como a arte e a ciência, cria uma atmosfera em que uma passa a ser mais importante e superior que a outra, quando as duas são infinitamente importantes para a estruturação da cultura de um povo e em uma determinada época. Isaac Asimov (1992, p. 35) apresentava essa preocupação quando afirmava que:

De certa forma é possível afirmar que a visão do Universo revelada pelo diligente esforço de quatro séculos empreendido pelos cientistas modernos ultrapassa amplamente a beleza e a majestade (para 
aqueles que se derem ao trabalho de observar) de todas as criações de todos os artistas reunidos, ou de toda imaginação dos mitologistas. Além disso, também é fato que, até o advento da moderna tecnologia, a fina flor da arte e do intelecto humano estava reservada aos aristocratas e os abastados. A ciência e a tecnologia modernas permitiram a edição de livros em grandes quantidades e a preços reduzidos, tornando acessíveis a todos a arte, a música e a literatura. Elas é que levaram as maravilhas da mente e da alma humanas até aos mais necessitados.

Por isso, e por outras razões já mencionadas, aproximar essas duas culturas não carece de grande esforço, pois elas estão tão unidas, não pelos padrões lógicos ou metodológicos, mas pelo interesse em conhecer e explicar a realidade, pelo uso constante da imaginação e da criação que devem estar sempre uma perto da outra, e levar essa proximidade para as crianças e os jovens é de grande valia para o ensino de ciências e principalmente de história da ciência.

\section{FICÇÃO CIENTÍFICA E HISTÓRIA DA CIÊNCIA: AS POSSIBILIDADES DIDÁTICAS DO CINEMA}

A ciência está presente em diferentes produções literárias, artísticas, didáticas ou, quando a utilizam para ilustrar a sua visão sobre os fenômenos a fim de se tornarem um tema discutido por tais produções. Quando falamos de produções que não são didáticas, ou não são realizadas visando ao uso na escola, podem livremente utilizar conceitos científicos, episódios da história da ciência, sem a preocupação com a veracidade dos fatos. Utilizar essas obras no ambiente escolar, na maioria dos casos as de ficção tanto literária quanto cinematográfica, pode despertar nos alunos um interesse pela história da ciência que até então não era estimulado pela educação formal, assim como declara Piassi (2012, p. 16):

Em todos os casos, supostamente, a ideia é levar em conta o destinatário do discurso: o jovem aluno. Tais materiais procuram estabelecer uma linguagem comum, trazer o interesse do aluno aos temas discutidos e, como vimos, eventualmente construir novos caminhos de raciocínio de compreensão de conceitos e relações. [...] De um modo ou de outro, acreditamos que a motivação para todos esses trabalhos advém em parte da compreensão de que o mundo midiático fora dos muros da escola interessa aos estudantes de uma forma mais evidente do que os conteúdos curriculares, da forma como são apresentados usualmente na escola. 
Mesmo levando em conta aspectos pedagógicos nos usos de materiais diversos no processo de ensino e aprendizagem, sempre é preciso ter um cuidado redobrado para não deixar que a prática não tenha significado para o objetivo de ensinar - no nosso caso, por exemplo, de ensinar a história da ciência. Elaborar bem o uso desses materiais de forma significativa para que exista com certeza um aprendizado sobre o tema deve ser obrigatório pelo professor ou pela escola. É por essa razão que alguns teóricos tinham uma preocupação no que diz respeito ao uso da ficção científica como recurso para se ensinar ciências.

A preocupação não gira somente em torno dos moldes nos quais o professor trabalhará com os materiais não pedagógicos no ensino de ciência, mas há também a preocupação a respeito do uso desses materiais, como a literatura e o cinema de ficção científica contribuir ainda mais para fixar no imaginário científico do aluno uma visão distorcida das produções científicas e dos que fazem ciência.

Turney declara sua preocupação quando observa os meios midiáticos e as formas com que eles tratam certos tipos de dilemas científicos, por um lado, leva informações do uso da ciência para os mais leigos, mas também pode direcionar de modo errôneo a reflexão que os mesmos irão fazer sobre tais fatos agora conhecidos, por isso, trabalhar com esses materiais em sala de aula necessita de uma elaboração cuidadosa por parte do professor. O autor afirma:

$\mathrm{Na}$ verdade, as histórias que envolvem as ciências são mais complexas do se imagina e elas podem desempenhar um papel importante no debate sobre as tecnologias na vida real. Tais histórias podem permitir que os leigos expressem seus sentimentos que, de outro modo, seriam difíceis de articular, mas que não devem ser ignorados. Elas podem, também, ajudar a informar as pessoas sobre os novos modos de pensar a respeito de aplicações reais e potenciais da ciência. Dessa forma, os detalhes dessas histórias e o modo pelo qual eles são invocados merecem atenção. (TURNEY, 2005, p. 98)

Carl Sagan, conhecido por ser um dos maiores divulgadores da ciência por meio de suas obras ficcionais tanto literárias quanto cinematográficas, também declara sua preocupação com a forma como a esfera midiática trata das produções científicas e dos cientistas. Afirma que os erros científicos que aparecem em séries de TV ou em filmes podem realizar um desserviço educacional, quando declara: 
Em todos esses programas, onde estão as alegrias da ciência? O prazer de descobrir como o Universo é formado? A satisfação de conhecer algo bem profundo? $\mathrm{E}$ o que dizer das contribuições cruciais que a ciência e a tecnologia deram para o bem-estar humano - ou os bilhões de vidas salvas ou viabilizadas pela tecnologia média e agrícola? (SAGAN, 1996, p. 361)

Essas preocupações também devem pairar a mente desses professores que se permitem trabalhar com a ciência utilizando não somente os materiais didáticos, mas também as produções midiáticas. Não é simples chegar na sala de aula, passar trechos de um filme ou ler parágrafos de uma obra de ficção cientifica e esperar que os alunos tirem as conclusões mais corretas, mas é desafiador e prazeroso, para ambos, alunos e professores, quando o entendimento a respeito de um conteúdo curricular se dá por meio de um material que reside fora dos muros da escola, tornese significativo.

É preciso sim ter cuidado, como já mencionamos mais de uma vez, mas tomando os cuidados necessários a experiência pode ser enriquecedora para o ensino de ciência e de história da ciência. Ao levarmos aos alunos temas da ciência que refletem o futuro da humanidade, podemos contribuir para que possam refletir sobre as suas práticas e tornarem-se mais críticos, mais conscientes. Piassi diz:

\begin{abstract}
Dessa forma, um dos critérios para considerar uma obra de ficção científica como de elevada qualidade é verificar em que medida ela inova ao lançar luzes sobre as questões que afetam nosso modo de vida, questões essas, pelo próprio caráter do gênero, vinculadas à ciência e à tecnologia. Tais obras acabam por se tornar uma referência simbólica, repercutindo em diversos âmbitos da cultura humana. Exemplos de obras desse tipo poderiam ser, entre outras, $A$ máquina do Tempo, de H. G. Wells, Admirável Mundo Novo, de Aldous Huxley, Eu, Robô, de Isaac Asimov, e 2001: Uma Odisseia no Espaço, o filme de Stanley Kubrick. Cada uma a seu modo, todas elas produziram questionamentos e repercussões ao estabelecerem novos modos de pensar sobre determinadas questões. Por conta disso, são obras que deveriam de alguma forma fazer parte da cultura escolar, particularmente nas disciplinas científicas. (PIASSI, 2007, p. 142, grifos do autor)
\end{abstract}

Desse modo, a ficção científica não é mais um instrumento midiático utilizado na sala de aula sem nenhum significado, ela pode ser um canal para desenvolver nos alunos uma consciência crítica sobre questões que estão relacionadas com a produção de conhecimento, com o avanço da ciência e da tecnologia e seus impactos na sociedade, promovendo uma preocupação e uma conscientização de 
temas que um aluno de ensino fundamental já pode começar a refletir para que enfim torne-se um adulto que possua por exemplo, uma consciência ambiental, tecnológica e contribua para os debates do mundo real.

Levar filmes que contam episódios da história da ciência pode ser valioso no que diz respeito à verdadeira compreensão da história da ciência, e também à construção de um caráter crítico em direção aos filmes e como eles retratam a ciência. $O$ cinema é capaz de contribuir com importantes maneiras de mergulhar nos estudos da História da Ciência, pois determinados filmes podem ser úteis para promover o questionamento de concepções de ciência, enquanto outros podem ser utilizados para ampliar informações e facilitar a compreensão de produção do conhecimento científico.

Portanto, o uso da ficção científica na sala de aula pode contribuir para o ensino de ciências e da história da ciência por conta da sua própria estrutura. A ficção científica, na literatura ou no cinema, possui como característica sua maneira própria de falar sobre a ciência, pois se propõe a propagar ideias, não apenas ensinando conceitos e teorias científicas, mas porque ela pode afetar as pessoas a respeito de questões do nosso mundo real, fazendo-as pensar, estimulando suas crenças e ideias sobre o futuro, conscientizando-as.

\section{CONSIDERAÇÕES FINAIS}

O presente texto buscou compartilhar propostas para trabalhar com a história da ciência em sua totalidade, utilizando outros recursos pedagógicos que não só os tradicionais, isto é, propor ensinar a história da ciência por meio das produções cinematográficas de ficção científica.

Mas a proposta firma-se no fato de que, ao ensinar a história da ciência, levam-se em conta todos os aspectos que influenciam a produção de conhecimento científico e todas as outras que refletem sobre a realidade na qual a ciência se encontra em cada período histórico. Dessa forma, utilizar a ficção científica não é só benéfico para se ensinar ciência e a história da ciência, mas, também, para propor reflexões a respeito da atuação da ciência na sociedade. 


\section{REFERÊNCIAS}

ALLEN, L. David. No Mundo da Ficção Científica. São Paulo: Summus, 1974.

ASIMOV, I. No mundo da ficção científica. Rio de Janeiro: Francisco Alves, 1984.

BRONOWSKI, Jacob. O olho visionário: ensaios sobre arte, literatura e ciência. Editora UNB, Brasília, 1998.

ECO, U. Obra aberta. 8. ed. São Paulo, Editora Perspectiva, 1991.

ENGLAND, Richard. Creative minds: the search for the reconciling principles of Science, the Humanities, Arts and Religions. Forum on Public Policy: a journal of Oxford Round Table, v. 2009, ํo 2.

GOMBRICH, E. H. A História da Arte. Rio de Janeiro: LTC, 2008.

GRANGER, Gilles-Gaston. A ciência e as ciências. São Paulo: UNESP, 1994.

KUHN, T. S. A estrutura das revoluções científicas. 3. ed. São Paulo: Perspectiva, 1991.

MASCARELLO, Fernando (Org.). História do cinema mundial. Campinas: Papirus, 2006.

MASSONI, Neusa Terezinha. Epistemologias do século XX. UFRGS, Instituto de Física, Programa da Pós-Graduação de Física. Porto Alegre, 2005.

PIASSI, L. P. C. Contatos: a ficção científica no ensino de ciências em um contexto sociocultural. 2007. 453 f. Tese (Doutorado) - Faculdade de Educação, Universidade de São Paulo, São Paulo, 2007.

PIASSI, L. P. C. Interfaces entre fantasia e ciência. Um estudo semiótico do filme: "2001: uma odisseia no espaço" como modelo de interpretação em perspectiva educacional. 2012. Tese (doutorado) - Escola de Artes e Ciências e Humanidades da Universidade de São Paulo, São Paulo, 2012.

ROSSI, Paolo. O nascimento da ciência moderna na Europa. Tradução: Antonio Angonese. Bauru, SP: Edusc, 2001.

SAGAN, Carl. O mundo assombrado pelos demônios: a ciência vista como uma vela no escuro. São Paulo: Companhia das Letras, 1996.

SNOW, C.P. As Duas Culturas e uma Segunda Leitura: uma versão ampliada das duas culturas e a revolução científica. EDUSP, São Paulo, 1995.

STAM, Robert. Introdução à teoria do cinema. Fernando Mascarello (Trad.). Campinas: Papirus, 2003.

TURNEY, Jon. Resposta popular à ciência e à tecnologia: ficção e o fator Frankenstein. In: MASSARANI, Luisa, et al. (org.). Terra incógnita: a interface entre ciência e público. Coleção Terra Incógnita, no 4. Rio de Janeiro: Vieira \& Lent: UFRJ, Casa da Ciência: FIOCRUZ, 2005.

ZANETIC, J. Física também é cultura. Tese de doutoramento, FEUSP, 1989.

ZANETIC, J.: Física e literatura: construindo uma ponte entre as duas culturas. História, Ciências, Saúde - Manguinhos, v. 13 (suplemento), p. 55-70, outubro 2006. 